\title{
Anaesthetic Management for Laparotomy in a patient with Ankylosing Spondylitis.
}

\section{Hasan $M R^{1}$, Sharmin $T^{2}$, Islam $M S^{3}$, Chowdhury $M R^{4}$, Islam $M Z^{5}$, Sharma $N^{6}$}

\begin{abstract}
It is a great challenge for an anaesthesiologist to manage a case of severely affected ankylosing spondylitis with limited available facilities as it produces lots of problem associated with it. We report a case where bilateral tranchal vagotomy and gastro-jejunostomy was done for gastric outlet obstruction in a patient of ankylosing spondylitis. This report giving importance of pre-anaesthetic assessment of any anatomical deformity and discussion of anaesthetic complications to be faced, decision of anaesthetic technique as well as proper
counseling of patient.
\end{abstract}

Key Words: 8, Charpara, Mymensingh, Bangladesh.

\section{Introduction}

Ankylosing spondylitis is a chronic inflammatory arthritic disease that result in fusion of the axial skeleton. Ankylosing spondylitis involves ossification of the axial ligaments progressing from the sacral lumber region cranially, resulting in a significant loss of mobility. These patient are a significant challenge to the anaesthesilogist with regard to airway management because of the reduce movement of their cervical spine and their temporomandibular joints. ${ }^{1}$
1. ${ }^{*}$ Dr. Mohammad Rajibul Hasan Assistant Professor Dept. of Anaesthesiology Community Based Medical College Mymensingh, Bangladesh.

2. Dr. Tahmina Sharmin Registrar, Dept. of Gynae \& Obs Mymensingh Medical College Mymensingh, Bangladesh.

3. Dr. Md. Shafiqut islam Senior consultant, Dept. of Surgery Mymensingh Medical College Hospital. Mymensingh, Bangladesh.

4. Dr. Mamunur Rashid Chowdhury Associate Professor, Dept. of Orthopedics Community Based Medical College Mymensingh, Bangladesh.

5. Dr. Md. Zahidul Islam Junior consultant, Dept. of Anaesthesiology Community Based Medical College hospital. Mymensingh, Bangladesh.

6. Dr. Netay Kumer Sharma Assistant Professor Dept. of Radialogy \& Imaging Community Based Medical College Mymensingh, Bangladesh.

Address of correspondence : Mobile: 01711161565

E-mail :wrijuta@yahoo.com 


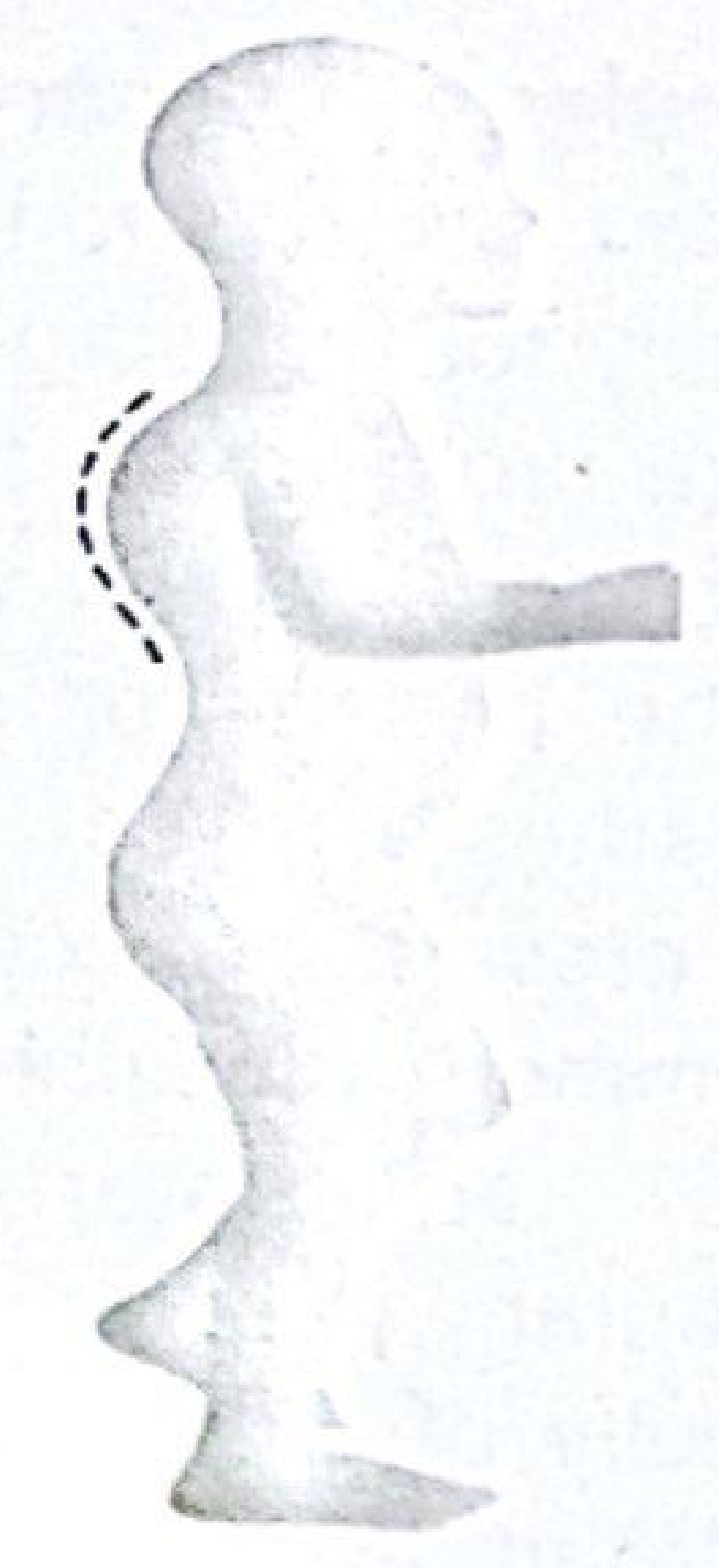

Fig: kyphosis

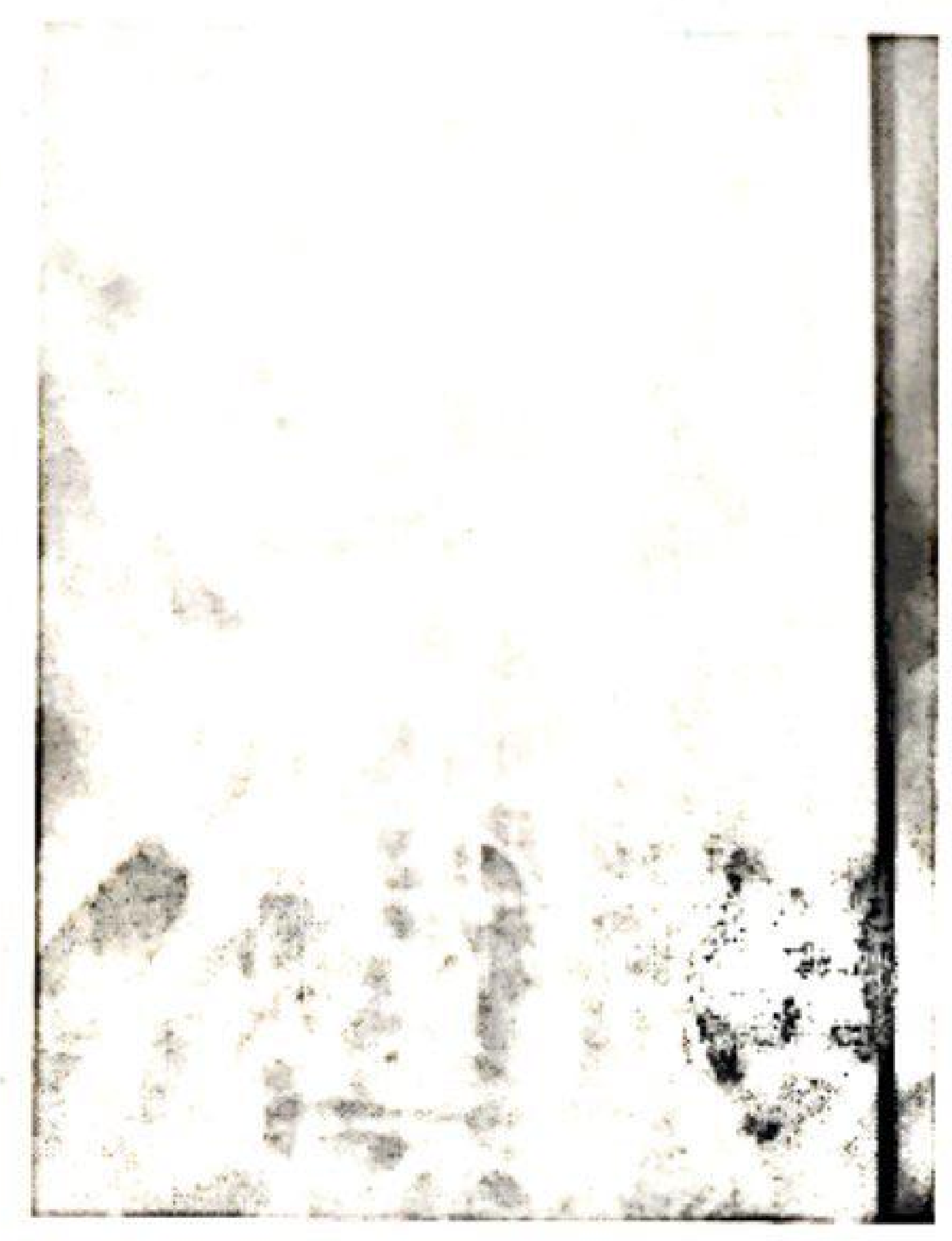

Fig: radiology shows bamboo spine of ankylosing spondylitis.

\section{Case report}

A 55 year old male with ankylosing spondylitis was admitted as a case of gastric outlet obstruction where vagotomy and gastrojejunostomy was done. The aim of our preoperative visit was proper counseling of patient and relatives, thorough assessment of airways and back and spine. The physical examination revealed "STOOPED POSTURE" on standing and being comfortable with 2 pillows under head, neck and upper back while sleeping. His vital parameters and systemic examination were within normal limit. Examination of airway shows mouth with full set of teeth, good mouth opening, restricted neck movement (side to side, flexion and extension - within 5-10 degree) with normal temporomandibular joints. His mallampati grade was 1 and wilson's risk score was 2 .

The thyromental and hyomental distance were within normal limit. Examination of back and spine shows loss of lumber lordosis, bamboo spine, kyphoscoliosis in the cervical and thoracic region with apparently normal intervertebral space.

Normal blood film and urine analysis. X-ray both hips shows osteoarthric changes, osteophytes with reduced joint space. X-ray cervical spine shows loss of cervical lordosis, syndesmophytes in upper four vertebrae with ankylosis of apophyseal joints. X-ray of lumbosacral spine shows degenerative changes osteophytes. X-ray chest- lung fields shows mild emphysematous changes.

Indirect laryngoscopy shows mobile vocal cords.

Temporomandibular joint movement was normal

After thorough discussion among ourselves and surgeons, about the potential risks and benefits of general anaesthesia compared with regional anaesthesia for vagotomy regional anaesthesiais not an option in this case, it was decided to do the operation under general anaesthesia.

After proper assessment, we found patient fit for anaesthesia with advice such as nothing by mouth with proper bowel preparation; inj. Diazepam $10 \mathrm{mg} \mathrm{i} / \mathrm{m}$ stat and inj. Ranitidine $50 \mathrm{mg}$ iv stat on pre-operative night. Provision for emergency tracheostomy is ready if needed.

In the morning, high risk informed written consent for anaesthesia was taken. inj. Atropine sulphate $0.3 \mathrm{mg}$ im and inj. Granisetron hydrochloride $1 \mathrm{mg}$ iv was given one hour before operation as pre-medication. The entire possible instrument for emergency and difficult intubation with tracheostomy tray, pulse oxymeter and laryngeal mask airways were kept ready. With gentle and caring hand the patient was in supine position on two 
pillows with proper support of head and neck. Pre-oxygenation was given with $6 \mathrm{~L} / \mathrm{min}$ oxygen flow for few minutes with face mask. Induction was done by inj. thiopental sodium 5 $\mathrm{mg} / \mathrm{kg}$ iv and oral intubation done by inj. suxamethonium chloride $1 \mathrm{mg} / \mathrm{kg}$ iv and 7.5 $\mathrm{mm}$ size endotracheal tube was introduced. Peri-operative anaesthesia was maintained by oxygen $2 \mathrm{~L} / \mathrm{min}$, nitrous oxide $4 \mathrm{~L} / \mathrm{min}$, and halothane. inj. Vecuronium bromide as neuromuscular blocking agent.

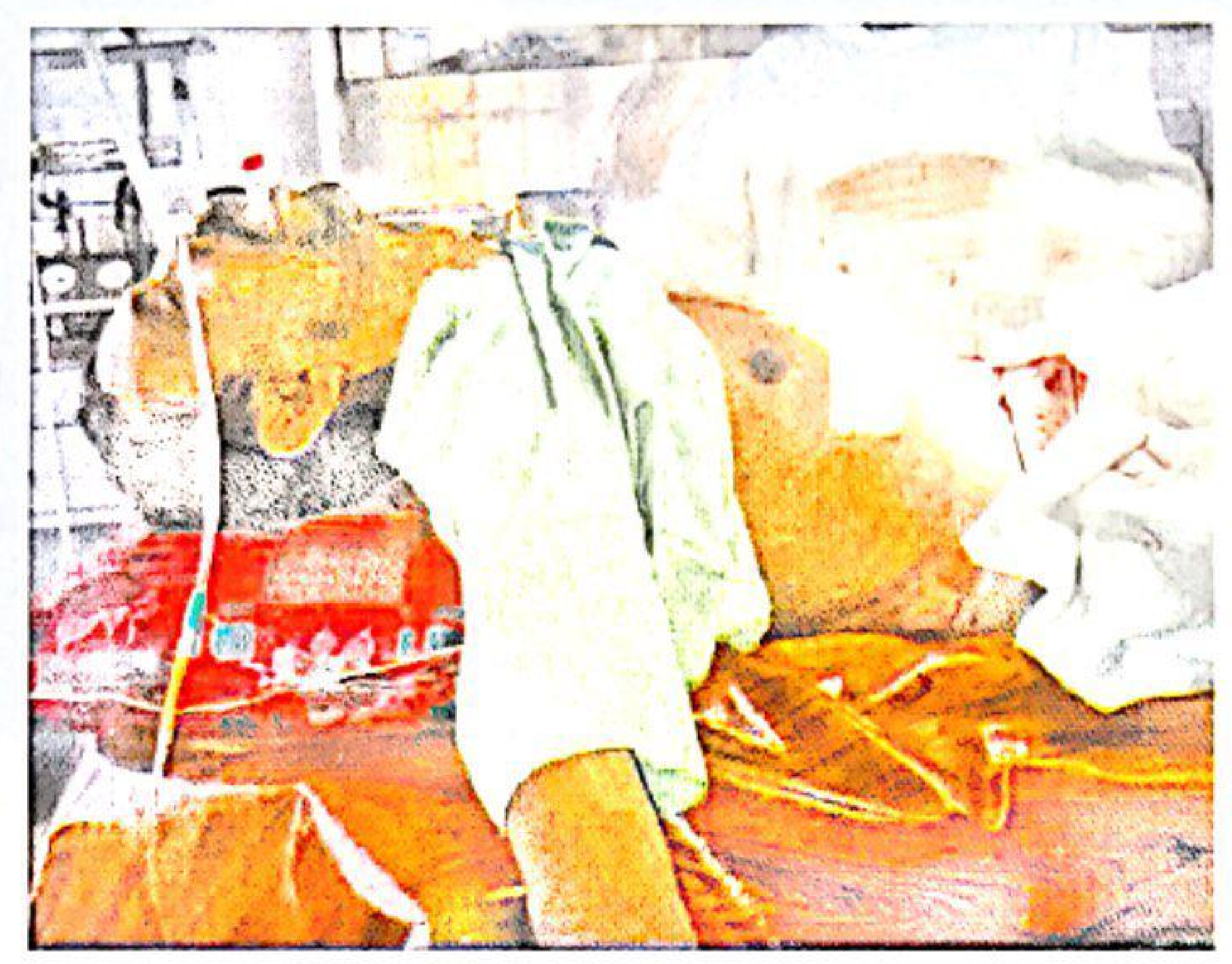

After end of the operation for $100 \%$ recovery $0.06 \mathrm{mg} / \mathrm{kg}$ Neostigmine and $0.03 \mathrm{mg} / \mathrm{kg}$ atropine were administered intravenously. The patient regained consciousness and spontaneous ventilation with adequate tidal volumes after a few minutes, then extubated in the operating room. He was comfortable and communicative postoperatively, without recall of intra-operative events.

\section{Discussion}

Ankylosing spondylitis is a progressive form of autoimmune inflammatory arthritis which leads to spontaneous fusion of vertebrae and sacroiliac joint. It often manifest as low back pain. Patients may develop many problems with their spine; like spine fracture even with minimal trauma, kyphotic deformity, poker spine, chest deformity and temporomandibular joint ankylosis. ${ }^{2}$ Ankylosing spondylitis affects $0.40 \%$ men \& $0.50 \%$ women. ${ }^{3,4}$ Involvement of the costochondral and costovertebrall joints results in limited chest expansion and impaired movement of the ribs. ${ }^{5}$ The temporomandibular, ${ }^{6}$ cricoarytenoid $^{7}$ and sacroiliac joints are also involved. The operative mortality for this surgery is $10 \% .^{8}$ In spite of all those problems of the patient; we decided to handle this patient very gently. So we prepared the patient for surgery under general anaesthesia. We started with oxygenation to prevent hypoxia due to chest deformity. A common anaesthetic problem in intubation is encountered due to temporomandibular joint ankylosis. The degree of difficulty of intubation may not be evident on a Mallampati score. ${ }^{9} \mathrm{~A}$ fiber optic laryngoscope can be used to put the tube down the trachea or in extreme cases tracheostomy is required. As we don't have facilities of fiberoptic laryngoscopy, we kept ready tracheostomy tray and laryngeal mask airway ready.

We achieved our goal by simple technique of general anaesthesia in spite of all problems and no unwanted complication was noticed.

\section{Conclusion}

This case report highlights the importance of proper pre anaesthetic assessment, thorough counseling and management of patient and good anaesthetic surgeon co-operation. Keeping in the mind all the possible complications, we achieved our goal with simple technique of general anaesthesia and routine monitoring devices. At last we want to say that, the success of such a complicated case fully depends on team work.

\section{Reference}

1. Miller: Miller's Anaesthesia, 7th edition, 2009, Churchill Livingstone.

2. Kumar K, Bhatt S, Dhimar A \& Parekh R: Anaesthetic Management for Total Hip Replacement in a case of Ankylosing Spondylitis: The Internet Journal of Anaesthesiology.2007 Volume 12 Number 2.

3. Kamarkar US, Chaudhari LS, Hosalkar H, Budhi $M$. Venkataraghavan D: Difficult intubation in acase of Ankylosing Spondylitis a case report: Journal of Postgraduate Medicine, India, 1998, volume: 44 , issue: 2 , page $-43-6$. 
4. Oryzlo MA, Rosen PS. Ankylosing spondylitis. Post Grad Med J 1969; 45:182-185.

5. Grimby J. Partitioning of the contribution of rib cage and abdomen to ventilation in ankylosing spondylitis, Thorax 1979; 29:178-179

6. Resnick D. Temporomandibular joint involvement in ankylosing spondylitis Radiology 1974; 112:587-91

7. Berendes J, Miehike A. A rare, ankylosis of the cricoarytenoid joints. Arch Otolaryngol 1973; 98:63-65.

8. Law WA. Ankylosing spondylitis and spinal astronomy. Proceedings of the Royal Society of Medicine, 1976; 69:715-20.

9. Muray GC, Persellin RH. Cervical Fracture complicating ankylosing spondylitis Am J Med 1981; 70:1033-41 